\title{
Preoperative cardiac risks in noncardiac surgery: the role of coronary angiography
}

\author{
Carlo Lombardi, Marco Sbolli, Dario Cani, Carlotta Perego, Gabriele Masini, \\ Marco Metra, Pompilio Faggiano \\ Cardiology Division, Spedali Civili Hospital and University of Brescia, Italy
}

\begin{abstract}
The preoperative evaluation of patients candidates to noncardiac surgery requires a knowledge of factors related both to type of surgery and to features of the single patient, potentially responsible for perioperative cardiovascular complications, fatal and nonfatal. The assessment of symptoms and/or noninvasive testing indicating the presence of coronary artery disease may suggest the need for medical therapy optimization and, eventually, coronary arteriography before the scheduled timing of noncardiac surgery. There is no evidence favoring a prophylactic myocardial revascularization (percutaneous or surgical) and more studies are needed to define the role of coronary artery disease diagnosis and treatment before high-risk non cardiac surgery.
\end{abstract}

\section{Introduction}

One of the most common requests made to clinical cardiologists is to assess the perioperative risks of cardiac events in patients undergoing noncardiac surgery. The increasing number of patients with known or unknown coronary artery disease undergoing non-cardiac surgery represents a current problem in clinical practice. The ability to predict cardiovascular complications after non-cardiac surgery is the key of optimal management in this high-risk setting of patients [1]. Acute coronary syndrome due to stress-induced rupture of a vulnerable atherosclerotic plaque and perioperative myocardial ischaemia secondary to the imbalance between demand and oxygen availability and substrates, frequently represent the underlying mechanisms of poor outcome after noncardiac surgery.

Corresponding author: Pompilio Faggiano, Cardiology Division, Spedali Civili, Piazza Spedali Civili, 25100 Brescia, Italy. Tel. +39.020 .3995571 . E-mail: cardiologia@pompiliofaggiano.it

Key words: Noncardiac surgery; preoperative evaluation; coronary arteriography.

Received for publication: 26 April 2017

Accepted for publication: 4 May 2017

(C) Copyright C. Lombardi et al., 2017

Tipografia PI-ME Editrice, Italy

Monaldi Archives for Chest Disease 2017; 87:863

doi: 10.4081/monaldi.2017.863

This article is distributed under the terms of the Creative Commons Attribution Noncommercial License (by-nc 4.0) which permits any noncommercial use, distribution, and reproduction in any medium, provided the original author(s) and source are credited.

\section{The preoperative risk stratification}

The perioperative cardiovascular management of these patients includes: preoperative risk assessment, diagnostic tests, pharmacogical management and post-surgical surveillance. American and European guidelines recommend a pre-operative cardiovascular risk stratification and divide patients in three groups: low-risk, intermediate-risk and high-risk, with estimated 30-day cardiac death or myocardial infarction $<1 \%, 1-5 \%$, and $>5 \%$, respectively $[2,3]$.

Surgical risk is usually estimated according to type of surgery or intervention considering also the timing of the surgery (elective $v s$ urgent $v s$ emergent). Many factors should be considered when assessing the perioperative or postoperative cardiac risk of event (Table 1). In general, the presence of cardiac and noncardiac comorbidities such as advanced age, valvular disease, diabetes, chronic kidney or pulmonary damage, malignancy, infections, mental disorders and especially current heart disease easily identify patients at higher risk for perioperative complications [4].

Moreover, the indirect estimate of the exercise tolerance as measured by metabolic equivalents (METs) of physical activities reported by the patient allows a stratification of the risk of events. Poor exercise tolerance, expressed by inability to climb two flights of stairs or run a short distance ( $<4$ METs) predicts worse perioperative outcomes especially after thoracic surgery [5].

Optimal medical management could minimize complications and improve survival after noncardiac sugery. A correct use of betablockers, angiotensin-converting enzyme inhibitors and angiotensinreceptor blockers, statins, aspirin and nitrates is crucial to optimize the control of cardiovascular risk factors and reduce the risk of perioperative myocardial ischemia, arrhythmias and the development of new onset left ventricular dysfunction.

Of great relevance is the debate on the use of beta-blockers. The importance of strict heart rate control as an independent predictor of outcome in cardiovascular disease and the perioperative increase of myocardial oxygen suggest the importance of cardioprotective efficacy of betablockers [6]. Numerous old studies have shown a significant reduction in cardiovascular events when beta-blocking therapy was administered preoperatively. Nevertheless, in the Perioperative Ischemic Evaluation Study (POISE) has been showed a $31 \%$ reduction in the risk of non-fatal MI with perioperative metoprolol compared with placebo, but patients treated with metoprolol were more likely to have a non fatal stroke or postoperative death [7]. A recent systematic review confirmed these results and evidenced that beta blockers started within 1 day or less before noncardiac surgery reduce the incidence acute myocardial infarction but increase the risk of stroke, death, hypotension, and bradycardia [8]. Guidelines recommended the use of perioperative beta-blockers in patients already receiving this medication, especially for high risk surgery, while they are not indicted in case of low risk scheduled surgery [2].

Optimal perioperative medical therapy in high-risk patients must also be focused on the stabilization of coronary plaques. Statins and as- 
pirin confer a benefit in patients with increased perioperative cardiac risk $[9,10]$. Discontinuation of aspirin and statins has been shown to increase the risk of acute coronary syndrome especially in patients with stable ischemic heart disease [11,12].

\section{Coronary arteries imaging}

The goal of effective risk stratification is to reduce risk of cardiovascular events. Accordingly, the use of noninvasive cardiac testing should be considered selectively in patients undergoing noncardiac surgery. Myocardial perfusion imaging, and exercise or dobutamine stress echocardiography are largely used to evaluate left ventricular function and to detect myocardial ischaemia [2,3]. In general, stress echocardiography has a high negative predictive value but low positive predictive values for perioperative cardiac events $[13,14]$.

Guidelines recommended the use of imaging stress testing especially before high-risk surgery in patients with more than two clinical risk factors and poor functional capacity ( $<4$ METs) [2].

Coronary angiography is usually not recommended for risk stratification in patients undergoing noncardiac surgery unless the patient has an independent indication for angiography [15]. The use of preoperative coronary angiography is recommended in patients with high- risk as result of a positive non invasive imaging stress testing and, obviously, in patients with recent instabilization of his/her coronary artery status (ACS) [2,3]. Lack of studies limits the real understanding of the potential usefulness of coronary artery imaging in non-cardiac surgery. The evidence of a significant coronary stenosis should also be evaluated in relation to the planned intervention. The interaction between cardiologists, anesthesiologists, surgeons and other specialists must consider the real need for myocardial revascularization because usually percutaneous angioplasty with stent implantation requires a prolonged double anti-platelet therapy that necessarily delays the time of noncardiac surgery; again, the recovery after coronary artery bypass surgery requires some weeks before a noncardiac surgery may be planned. Actually, there are few controlled randomized trials that have investigated the effects of percutaneous revascularization before noncardiac surgery. In the Coronary Artery Revascularization Prophylaxis (CARP) study, 510 patients with ischemic heart disease were assigned to receive preoperative coronary artery revascularization (percutaneous or surgical) before elective vascular surgery. The results showed no differences in mortality ( $22 \%$ vs $23 \%, \mathrm{p}=0.92)$ and postoperative myocardial infarction ( $12 \%$ vs $14 \%, \mathrm{p}=0.37)$ in the revascularization compared with control group [16]. Different result were found in 426 patients candidate to elective carotid endarterectomy affected by asymptomatic coronary artery disease [17]. The primary combined

Table 1. Assessing the perioperative or postoperative cardiac risk of event.

\begin{tabular}{|c|c|c|c|}
\hline \multicolumn{4}{|l|}{ Patients risk factor } \\
\hline \multicolumn{4}{|l|}{ Age } \\
\hline \multicolumn{4}{|l|}{ Previous surgery } \\
\hline Poor status & $\begin{array}{l}\text { Frailty } \\
\text { Depression } \\
\text { Dementia } \\
\text { Absence of family support }\end{array}$ & & \\
\hline Non cardiac comorbidities & $\begin{array}{l}\text { Diabetes } \\
\text { Chronic pulmonary dysfunction } \\
\text { Kidney injury } \\
\text { Obesity } \\
\text { Anemia } \\
\text { Malignancy } \\
\text { Infection }\end{array}$ & & \\
\hline Cardiac diseases & $\begin{array}{l}\text { Ischaemia heart disease } \\
\text { Cardiomyopathy (hypertrophic, rest } \\
\text { Valvular disease } \\
\text { Heart failure } \\
\text { Arrhythmias } \\
\text { Previous cardiac surgery } \\
\text { Implantable devices }\end{array}$ & ve, idiopathic) & \\
\hline Medical therapy & $\begin{array}{l}\text { Non optimal medical treatment } \\
\text { Poor adherence }\end{array}$ & & \\
\hline \multicolumn{4}{|l|}{ Surgery-related factors } \\
\hline Type of surgery & $\begin{array}{l}\text { Low-risk: }<1 \% \\
\text { (e.g., breast, dental, } \\
\text { thyroid, eye, carotid asymptomatic, } \\
\text { gynecology: minor, orthopedic } \\
\text { as meniscectomy transurethral } \\
\text { resection of the prostate) }\end{array}$ & $\begin{array}{l}\text { Intermediate-risk: 1-5\% } \\
\text { (e.g., Intraperitoneal, carotid } \\
\text { symptomatic, Peripheral arterial } \\
\text { angioplasty, endovascular } \\
\text { aneurysm repair, head and neck } \\
\text { surgery, hip and spine surgery, } \\
\text { Renal transplant, intra-thoracic } \\
\text { surgery) }\end{array}$ & $\begin{array}{l}\text { High-risk: }>5 \% \\
\text { (e.g., aortic and major vascular } \\
\text { surgery lower limb revascularization } \\
\text { or amputation or thromboembolectom, } \\
\text { duodeno-pancreatic surgery, } \\
\text { liver resection, oesophagectomy, } \\
\text { cystectomy, pneumonectomy, } \\
\text { pulmonary or liver transplant }\end{array}$ \\
\hline Time of surgery & Elective & Urgent & Emergency \\
\hline Type of anesthesia & Local & General & \\
\hline
\end{tabular}


endpoint was the incidence of any myocardial ischemic events associated with the procedure. No myocardial event after carotid endoarteriectomy was observed in patients undergoing prophylactic percutaneous revascularization while myocardial infarction occurred in 9 patients in the control group ( $p>0.001)$. A secondary analysis of this non blinded trial confirmed a long-term usefulness of systematic coronary angiography with a significate reduction in myocardial infarction risk (mean follow-up 2.5 years) for patients receiving coronary angiography compared with control group (HR 078; 95\% CI, 0.024-0.256; $\mathrm{p}<0.001$ ) [18].

In a meta-analysis of 10 studies including 3949 patients, use of prophylactic coronary revascularization compared with optimal medical treatment before high-risk noncardiac surgery did not confer any advantages in long-term survival and reduction in myocardial perioperative infarction and adverse cardiac events [19].

Routine use of coronary angiography and revascularization in patients who have to undergo noncardiac surgery is not definitively supported by the studies conducted. The lack of prospective clinical randomized trials encourages researchers to invest more resources in this area of medicine.

Percutaneous or surgical coronary intervention should be reserved only in patients with an acute coronary syndrome or stable angina symptoms refractory to optimal medical therapy and/or high risk features on noninvasive testing.

\section{References}

1. Devereaux PJ, Chan MT, Alonso-Coello P, et al. Vascular events in noncardiac surgery patients cohort evaluation Study I, Association between postoperative troponin levels and 30-day mortality among patients undergoing noncardiac surgery. JAMA 2012;307:2295-304.

2. Kristensen SD, Knuuti J, Saraste A, et al. 2014 ESC/ESA Guidelines on non-cardiac surgery: cardiovascular assessment and management: The Joint Task Force on non-cardiac surgery: cardiovascular assessment and management of the European Society of Cardiology (ESC) and the European Society of Anaesthesiology (ESA). Eur J Anaesthesiol 2014;31:517-73.

3. Fleisher LA, Fleischmann KE, Auerbach AD et al. 2014 ACC/AHA guideline on perioperative cardiovascular evaluation and management of patients undergoing noncardiac surgery: executive summary: a report of the American College of Cardiology/American Heart Association Task Force on Practice Guidelines. Circulation 2014;130:2215-45.

4. Wirthlin DJ, Cambria RP. Surgery-specific considerations in the cardiac patient undergoing noncardiac surgery. Prog Cardiovasc Dis 1998;40:453-68.

5. Buccard BM. Relationship between the inability to climb two flights of stairs and outcome after major non-cardiac surgery: implications for the pre-operative assessment of functional capacity. Anaesthesia 2005;60:588-93.

6. Lu WJ, Hoeks SE, van Kuijk JP, Bax JJ, Poldermans D. Treatment recommendations to prevent myocardial ischemia and infarction in patients undergoing vascular surgery. Curr Treat Options Cardiovasc Med 2009;11:33-44.
7. Devereaux PJ, Yang H, Yusuf S, et al. for the POISE Study Group: Effects of extended-release metoprolol succinate in patients undergoing non-cardiac surgery (POISE trial): a randomised controlled trial. Lancet 2008;371:1839-47.

8. Wijeysundera DN, Duncan D, Nkonde-Price C, et al. Perioperative beta blockade in noncardiac surgery: a systematic review for the 2014 ACC/AHA guideline on perioperative cardiovascular evaluation and management of patients undergoing noncardiac surgery: a report of the American College of Cardiology/American Heart Association Task Force on Practice Guidelines. Circulation 2014;130:2246-64.

9. Schouten O, Boersma E, Hoeks SE, et al. Fluvastatin and peri-operative events in patients undergoing vascular surgery. $\mathrm{N}$ Engl J Med 2009;361:980-9.

10. Smith SCJr, Allen J, Blair SN, et al. AHA/ACC guidelines for secondary prevention for patients with coronary and other atherosclerotic vascular disease: 2006 update: endorsed by the National Heart, Lung, and Blood Institute. Circulation 2006;113:2363-72. Correction: Circulation 2006;113:e847.

11. Biondi-Zoccai GGL, Lotrionte M, Agostoni P, et al. A systematic review and meta-analysis on the hazards of discontinuing or not adhering to aspirin among 50279 patients at risk for coronary artery disease. Eur Heart J 2006;27:2667-74.

12. Schouten 0, Hoeks SE, Welten GMJM, et al. Effect of statin withdrawal on frequency of cardiac events after vascular surgery. Am J Cardiol 2007;100:316-20.

13. Das MK, Pellikka PA, Mahoney DW, et al. Assessment of cardiac risk before nonvascular surgery: dobutamine stress echocardiography in 530 patients. J Am Coll Cardiol 2000; 35:1647-53.

14. Shaw LJ, Eagle KA, Gersh BJ, Miller DD. Meta-analysis of intravenous dipyridamole-thallium-201 imaging (1985 to 1994) and dobutamine echocardiography (1991 to 1994) for risk stratification before vascular surgery. J Am Coll Cardiol 1996; 27:787-98.

15. Hamm CW, Bassand JP, Agewall S, et al. ESC Guidelines for the management of acute coronary syndromes in patients presenting without persistent ST-segment elevation: The Task Force for the management of acute coronary syndromes (ACS) in patients presenting without persistent ST-segment elevation of the European Society of Cardiology (ESC). Eur Heart J 2011;32:2999-3054.

16. McFalls EO, Ward HB, Moritz TE, et al. Coronary-artery revascularization before elective major vascular surgery. N Engl J Med 2004;351:2795-804.

17. Illuminati G, Ricco JB, Greco C, et al. Systematic preoperative coronary angiography and stenting improves postoperative results of carotid endarterectomy in patients with asymptomatic coronary artery disease: a randomised controlled trial. Eur J Vasc Endovasc Surg 2010;39:139-45.

18. Illuminati G, Schneider F, Greco C, et al. Long-term results of a randomized controlled trial analyzing the role of systematic pre-operative coronary angiography before elective carotid endarterectomy in patients with asymptomatic coronary artery disease. Eur J Vasc Endovasc Surg 2015;49:366-74.

19. Wong EY, Lawrence HP, Wong DT. The effects of prophylactic coronary revascularization or medical management on patient outcomes after noncardiac surgery-a meta-analysis. Can J Anaesth 2007;54:705-17. 